\title{
TAMANHO ÓTIMO DE PARCELA PARA ESTIMATIVA DE ESTOQUE DE CARBONO DA PARTE AÉREA LENHOSA DE FITOFISIONOMIAS FLORESTAIS NA AMAZÔNIA ORIENTAL
}

\author{
André Luiz Menezes Vianna ${ }^{1}$, Edson José Vidal ${ }^{2}$, Maurício Romero Gorenstein ${ }^{3}$, \\ João Luís Ferreira Batista ${ }^{2}$
}

\author{
${ }^{1}$ Eng. Florestal, ESALQ/USP, Piracicaba, SP, Brasil - almvianna@gmail.com \\ ${ }^{2}$ Eng. Agrônomo, Dr., Depto. de Ciências Florestais, ESALQ/USP, Piracicaba, SP, Brasil - \\ edvidal@esalq.usp.br - parsival@esalq.usp.br \\ ${ }^{3}$ Eng. Florestal, Doutorando em Recursos Florestais, ESALQ/USP, Piracicaba, SP, Brasil - mrgorens@esalq.usp.br
}

Recebido para publicação: 19/09/2008 - Aceito para publicação: 26/07/2009

\begin{abstract}
Resumo
Este trabalho foi realizado na fazenda Jutaituba, localizada no município de Portel, Pará. O estudo foi realizado por meio de um inventário piloto com finalidade de estimar o estoque de carbono da parte aérea lenhosa de diferentes fitofisionomias encontradas na propriedade analisada. $\mathrm{O}$ objetivo deste trabalho foi analisar o tamanho de parcela ideal para ser utilizado no inventário amostral definitivo. Utilizou-se amostragem estratificada e 30 unidades amostrais de dimensão 10 × $250 \mathrm{~m}\left(2500 \mathrm{~m}^{2}\right)$, onde mediu-se o CAP de todos os indivíduos vivos com DAP maior ou igual a $10 \mathrm{~cm}$. Para a análise de tamanho de parcela, utilizou-se o método de coeficiente de correlação intraclasse. Através do inventário piloto, estimou-se a média do estoque de carbono na parte aérea lenhosa de 188,54 Mg.C.ha ${ }^{-1}\left(143,07\right.$ a 234,02 Mg.C.ha $\left.{ }^{-1}\right)$, com erro amostral de 24\% com 95\% de significância. Portanto, para um erro amostral de $10 \%$ com $95 \%$ de significância, seriam necessárias 187 unidades amostrais. De acordo com os resultados do estudo, determinou-se que o tamanho ótimo da unidade amostral a ser utilizada no inventário amostral definitivo será de 10 × 200 m (2000 m²).

Palavras chave: Inventário florestal; biomassa; unidade amostral.
\end{abstract}

\begin{abstract}
Optimum plot size for estimate carbon stock from above ground tree biomass from phytophysiognomies in Eastern Amazon. This work was developed in Jutaituba farm, located in the county of Portel, Pará. The study was carried out by means of a pilot inventory with the purpose of estimating the carbon stock in above ground tree biomass from various phytophysiognomies found in the analyzed property. The main goal of this effort is to analyze the size of the ideal plot to be utilized in the definitive inventory. It was used Stratified Sampling and sample unities with dimensions of $10 \times 250 \mathrm{~m}\left(2500 \mathrm{~m}^{2}\right)$, in wich all the living individuals' measured CAP shown a DAP above $30 \mathrm{~cm}$. For the plot size analysis it was utilized the Intraclass Correlation Coefficient method. Through the pilot inventory it was estimated the carbon stock average in above ground tree biomass of $188,54 \mathrm{Mg}$ C.ha ${ }^{-1}\left(143,07\right.$ a $\left.234,02 \mathrm{Mg} \mathrm{C}^{-1} \mathrm{a}^{-1}\right)$ with a sampling error of $24 \%$ and $95 \%$ significance. Therefore, for a sampling error of $10 \%$ and $95 \%$ significance it would be needed 187 sample unities. By means of the plot size study, the size of the plot could be reduced as a way to reduce the costs of the inventory without harm to the estimations of the variable of interest. The dimension of the sampling unity to be utilized in the definitive inventory will be $10 \times 200 \mathrm{~m}\left(2000 \mathrm{~m}^{2}\right)$.

Keywords: Forest inventory; biomass; sample unities.
\end{abstract}

\section{INTRODUÇÃO}

As emissões brasileiras oriundas de desmatamento são fontes de controvérsias e preocupação, uma vez que os números apresentados pelas diversas autoridades variam desde zero até os valores do mesmo nível que a emissão proveniente de toda a frota mundial de automóveis (FEARNSIDE, 2001). A magnitude das emissões brasileiras depende de parâmetros básicos, tais como taxa de desmatamento, biomassa e absorção de 
carbono pela paisagem que substitui a floresta (FEARNSIDE, 2001). Dessa forma, tem-se a necessidade de se obter uma estimativa do estoque de carbono nas formações florestais que, se queimadas e/ou removidas, agravarão o processo de aquecimento global. Estimativas de biomassa variam muito, tanto na magnitude dos dados quanto nos procedimentos de cálculo (FEARNSIDE, 2001), além da grande variabilidade de biomassa decorrente da tipologia amostrada. De acordo com dados provenientes do Primeiro Inventário Brasileiro de Emissões Antrópicas de Gases de Efeito Estufa (MINISTÉRIO DA CIÊNCIA E TECNOLOGIA, 2006), há diferença para a biomassa estimada entre as tipologias amostradas neste trabalho, variando de 101 toneladas por hectare para campo aluvial a 140 toneladas por hectare para Floresta Ombrófila Densa. Para a região de Paragominas (PA), Gerwing; Vidal (2002) estimaram a biomassa viva acima do solo de floresta intacta, mensurando os indivíduos com DAP superior ou igual a $10 \mathrm{~cm}$, em 309 toneladas por hectare, o que corresponderia a 154,5 toneladas de carbono por hectare.

Essa variação existente mostra a importância da quantificação do estoque de carbono no sítio estudado. A estimativa do estoque de carbono da vegetação pode ser obtida por método direto ou indireto. $\mathrm{O}$ método direto se dá através da derrubada e pesagem de todas as árvores que ocorrem em parcelas fixas, no entanto esse método se baseia em poucas parcelas, pequenas e tendenciosamente escolhidas (HIGUCHI, 2004). No método indireto, as estimativas são produzidas a partir de dados de inventários florestais, em que se estima a biomassa a partir do volume da madeira, usando-se a densidade média da madeira e um fator de correção para árvores com DAP $<25 \mathrm{~cm}$ (HIGUCHI, 2004). Obtém-se o estoque de carbono através do produto da concentração de carbono pela biomassa da vegetação. A concentração de carbono na vegetação está em torno de $48 \%$, valor este que está dentro dos limites de concentração em florestas tropicais, entre 46 e $52 \%$ (HIGUCHI; CARVALHO JR., 1994). Em vista da importância da estimativa de carbono por métodos indiretos, há necessidade de um adequado planejamento, uma vez que o custo de inventário florestal é elevado, ainda mais em áreas extensas, como as que são predominantes na região Amazônica.

Como forma de planejamento, deve-se determinar o tamanho e a forma das unidades amostrais utilizadas no levantamento. De acordo com Batista (2006), parcela é o tipo de unidade amostral mais utilizado em levantamentos florestais, mas sua forma e tamanho variam bastante em função do tipo de floresta e objetivo do levantamento florestal. Não existe um método específico para se estabelecer o tamanho ideal de uma parcela, mas sim vários métodos, dentre os quais o método do coeficiente de correlação intraclasse. Esse método possui as seguintes vantagens: permite incorporar o custo de acesso e outros custos ligados à instalação das parcelas, não se restringe a alguns tamanhos predeterminados e é possível aplicá-lo com base em um único levantamento de campo, utilizando um único tamanho de parcela (BATISTA, 2006). Queiroz (1977) avaliou o tamanho ideal de parcelas para estimativa de volume em Tapajós, utilizando o coeficiente de correlação intraconglomerados. Em seu estudo, ele verificou que os seguintes itens têm influência sobre o tamanho ideal: a razão entre custo de penetração nas subunidades e mensuração, o coeficiente de correlação e a área da subunidade amostrada.

O objetivo deste trabalho é discutir e avaliar o tamanho de parcela ótimo para estimativa do estoque de carbono na parte aérea lenhosa encontrada na vegetação da Fazenda Jutaituba, município de Portel (PA), pertencente à Empresa Martins Agropecuária.

\section{METODOLOGIA}

\section{Área de estudo}

Este estudo foi realizado na fazenda Jutaituba, pertencente à Empresa Martins Agropecuária

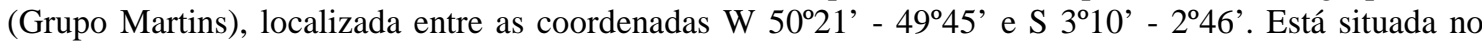
município de Portel, no estado do Pará, e possui uma área total de 142.439,7 ha.

A propriedade está inserida em uma região cujo clima é classificado por Köppen como tropical úmido (Amw), caracterizado por apresentar chuvas do tipo monção e uma estação seca de pequena duração, mas com umidade suficiente para alimentar a floresta tropical. De acordo com Radam (1974), recebe anualmente $2.400 \mathrm{~mm}$ de chuva, a temperatura média do ar é de $26{ }^{\circ} \mathrm{C}$ e a umidade relativa superior a $85 \%$. O solo predominante na região é o LATOSSOLO Amarelo Distrófico, textura argilosa, e o LATOSSOLO Amarelo Distrófico Concrecionário, textura argilosa (EMBRAPA, 1999).

O levantamento ocorreu em uma área total de 134.435,95 ha e abrange as 6 tipologias florestais encontradas na propriedade. Esses ambientes fitoecológicos encontrados na área foram classificados e descritos com base na terminologia adotada pelo Radam (1974). 
As fitofisionomias inventariadas foram: Floresta Aluvial, Campo Aluvial, Floresta Ombrófila Aberta com cipó explorada seletivamente, Floresta Ombrófila Densa, Floresta Ombrófila Aberta com cipó e Várzea Alta.

\section{Procedimento de campo}

A estimativa do estoque de carbono se deu por meio de inventário florestal piloto, método indireto, com o objetivo de obtenção da biomassa viva acima do solo. Realizou-se amostragem estratificada, em que cada tipologia florestal caracterizou um estrato. Em cada estrato utilizou-se amostragem aleatória simples.

Como unidades amostrais, foram utilizadas parcelas lançadas de forma aleatória, com dimensões de $10 \times 250 \mathrm{~m}\left(2.500 \mathrm{~m}^{2}\right)$. Cada parcela foi subdividida em 5 subparcelas $(\mathrm{k})$, com as dimensões $10 \times 50 \mathrm{~m}\left(500 \mathrm{~m}^{2}\right)$. As unidades amostrais foram instaladas a pelo menos $50 \mathrm{~m}$ do limite da floresta. A direção delas foi estabelecida, também de forma aleatória, através de miradas na bússola, de forma a evitar ultrapassar o limite da floresta.

As observações foram tomadas por subparcelas, medindo-se a circunferência à altura do peito $(1,30 \mathrm{~m})$ do solo de todos os indivíduos vivos, inclusive palmeiras e cipós, que possuíam DAP (diâmetro à altura do peito ou $1,30 \mathrm{~m}$ ) superior a $10 \mathrm{~cm}$.

Uma vez que o objetivo deste inventário foi a obtenção de estimativa de biomassa, não se identificou por espécie os indivíduos amostrados, apenas através do nome local utilizado por mateiros da região. Os indivíduos foram ainda subdivididos em espécies pioneiras (gêneros Cecropia e Vismia), árvores não-pioneiras, palmeiras e cipós.

Obteve-se um total de 30 parcelas amostradas (n) ou 150 subparcelas (nk), divididas pelas 6 tipologias florestais, de acordo com a área de cada uma e possibilidade de acesso. O número de unidades amostrais por fitofisionomia está descrito na tabela 4.

\section{Cálculo do estoque de carbono}

Estimou-se o peso seco de cada indivíduo através de método indireto, inventário florestal. As equações de regressão adequadas para cada subdivisão criada são apresentadas na tabela 1 .

Tabela 1. Equações alométricas para estimativa de peso seco.

Table 1. Allometric equations for estimating dry matter.

\begin{tabular}{|c|c|c|c|}
\hline Grupo de espécies & Equação de regressão & Fonte & $\begin{array}{l}\text { Local do estudo } \\
\end{array}$ \\
\hline Não-pioneiras & $\mathrm{PS}=0,465 *(\mathrm{DAP})^{2.202}$ & $\begin{array}{l}\text { Overman et al. (1994), citado } \\
\text { em Gerwing; Vidal (2002) }\end{array}$ & $\begin{array}{l}\text { Paragominas (PA), } \\
\text { Amazônia Oriental }\end{array}$ \\
\hline \multicolumn{4}{|l|}{ Pioneiras } \\
\hline Cecropia sp. & $\ln (\mathrm{PS})=-2.512+2.426 \ln (\mathrm{DAP})$ & $\begin{array}{l}\text { Nelson et al. (1999), citado } \\
\text { em Gerwing; Vidal (2002) }\end{array}$ & $\begin{array}{l}\text { Paragominas (PA), } \\
\text { Amazônia Oriental }\end{array}$ \\
\hline Vismia sp. & $\ln (\mathrm{PS})=-1.997+2.413 \ln (\mathrm{DAP})$ & $\begin{array}{l}\text { Nelson et al. (1999), citado } \\
\text { em Gerwing; Vidal (2002) }\end{array}$ & $\begin{array}{l}\text { Paragominas (PA), } \\
\text { Amazônia Oriental }\end{array}$ \\
\hline \multicolumn{4}{|l|}{ Palmeira } \\
\hline $\begin{array}{l}\text { Euterpe oleracea } \\
\text { (açaí) }\end{array}$ & $\mathrm{PS}=\exp (-0,0470+0,0750 * \mathrm{DAP})$ & $\begin{array}{l}\text { Bartelt et al. (2000), citado } \\
\text { por Santos et al. }(2004)\end{array}$ & $\begin{array}{l}\text { Cametá (PA), } \\
\text { Amazônia Oriental }\end{array}$ \\
\hline Cipó & $\log (\mathrm{PS})=0,07+2.17 \log (\mathrm{DAP})$ & Gerwing; Lopes (2000) & $\begin{array}{l}\text { Paragominas (PA), } \\
\text { Amazônia Oriental }\end{array}$ \\
\hline
\end{tabular}

DAP: diâmetro à altura do peito; OS: peso seco.

Com o peso seco, pode-se determinar o teor de carbono, multiplicando a biomassa seca de cada indivíduo pelo fator 0,48. De acordo com Higuchi; Carvalho Jr. (1994), a concentração de carbono de um indivíduo arbóreo é de $48 \%$ de seu peso seco. O somatório do teor de carbono de cada indivíduo permitiu obter-se o estoque de carbono por parcela.

\section{Análise de tamanho ótimo de parcela}

A análise de tamanho ótimo de parcela foi realizada através do método do coeficiente de correlação intraclasse, e a apresentação abaixo segue Hansen et al. (1953), segundo o detalhamento de Batista (2006). 
A variável de interesse a ser avaliada foi estoque de carbono em megagramas por hectare. As observações foram tomadas em 30 parcelas (n), compostas por 5 subparcelas (k) de dimensões já descritas no item anterior, que resultaram em 150 (nk) unidades amostrais. Através de amostragem aleatória simples (AAS) dessas unidades amostrais, pode-se identificar duas fontes de variação aleatória: a variância entre parcelas e a variância entre subparcelas dentro da parcela.

Essas variâncias foram estimadas para a área total e para cada tipologia, através dos quadrados médios de um modelo de análise de variância hierárquica com essas duas fontes de variação.

As variâncias dentro e entre são definidas por dois parâmetros: variância das subparcelas e o coeficiente de correlação intraclasse, que mede a correlação entre as subparcelas dentro de parcelas. Portanto, estabeleceram-se esses dois parâmetros também para a área total e para cada tipologia, através dos seguintes estimadores:

Coeficiente de correlação intraclasse:

$$
\hat{\rho}=\frac{S_{E}^{2}-S_{D}^{2}}{S_{E}^{2}+(k-1) S_{D}^{2}}
$$

cujos limites são: limite superior $\hat{\rho}=1$, limite inferior $\hat{\rho}=-1 /(k-1)$.

Em que: $\quad \mathrm{S}_{\mathrm{E}}^{2}=$ variância entre parcelas;

$\mathrm{S}_{\mathrm{D}}^{2}=$ variância dentro das parcelas;

$\mathrm{K}=$ número de subparcelas.

Variância populacional (variância entre subparcelas, como se fossem medidas numa AAS):

$$
\hat{\sigma}=\frac{S_{E}^{2}+(k-1) S_{D}^{2}}{k}
$$

Em que: $\quad \mathrm{S}_{\mathrm{E}}^{2}=$ variância entre parcelas;

$\mathrm{S}_{\mathrm{D}}^{2}=$ variância dentro das parcelas;

$\mathrm{K}=$ número de subparcelas.

Através das estimativas da variância das subparcelas e do coeficiente de correlação intraclasse, pode-se estabelecer a variância da média amostral, para a área total e para cada tipologia, em termos de megagramas de carbono por hectare, através do seguinte estimador:

$$
\operatorname{Var}\{\widehat{\mu}\}=\frac{\sigma^{2}}{n k}[1+(k-1) \rho]
$$

Em que: $\quad \sigma^{2}=$ variância populacional;

$\mathrm{P}=$ coeficiente de correlação intraclasse;

$\mathrm{Nk}=$ número de unidades amostrais.

Como forma de incluir os custos do inventário, estabeleceram-se diferentes custos em função do tempo de acesso e de medição das parcelas amostradas. Desses custos, calcularam-se diferentes razões entre o custo (tempo em minutos) de acesso à parcela e o de medição dela.

Essas razões, juntamente com o valor do coeficiente de correlação intraclasse, possibilitaram o cálculo do tamanho de parcela ótimo através do número de subparcelas necessárias. Esse cálculo foi realizado tanto para área total como por tipologia e se procedeu da seguinte forma:

$$
k^{*}=\sqrt{\frac{C_{A}}{C_{M}} \frac{k S_{D}^{2}}{S_{E}^{2}-S_{D}^{2}}} \approx \sqrt{\frac{C_{A}}{C_{M}} \frac{1-\rho}{\rho}}
$$

Em que: $\quad \mathrm{k}^{*}=$ número ideal de subparcelas;

$\mathrm{C}_{\mathrm{A}}=$ custo de acesso à parcela;

$\mathrm{C}_{\mathrm{M}}=$ custo de medição da parcela;

$\rho=$ coeficiente de correlação intraclasse. 


\section{RESULTADOS}

\section{Resultados do inventário piloto}

Estimativa de carbono

Estimou-se a média do estoque de carbono na parte aérea lenhosa em 188,54 megagramas de carbono por hectare, com variação de 143,07 a 234,02 megagramas de carbono por hectare. Para a área total, teríamos um estoque de 25.346.662,96 megagramas, com variação de 19.233.092,67 a $31.460 .233,26$ megagramas. O erro amostral para a área total foi de $24 \%$ em termos da estimativa média de carbono por hectare, com 95\% de significância. O coeficiente de variação encontrado foi de 56,57 megagramas de carbono por hectare. A tabela 2 resume os resultados por tipologia florestal.

A tabela 2 ainda indica o erro amostral obtido por este levantamento para cada estrato, assim como o coeficiente de variação em termos da média obtida em cada tipologia florestal.

Tabela 2. Estratificação e planejamento do inventário definitivo para um erro amostral de $10 \%$ da média com 95\% de significância. Variável: estoque de carbono por hectare.

Table 2. Estratification and planning of the definitive inventory for a $10 \%$ average sampling error and 95\% significance. Variable: carbon stock per hectare.

\begin{tabular}{|c|c|c|c|c|c|c|c|}
\hline \multirow{2}{*}{ Estrato } & \multicolumn{2}{|c|}{ Área } & \multirow{2}{*}{$\begin{array}{c}\text { C Médio } \\
\left(\text { Mg.C.ha }^{-1}\right)\end{array}$} & \multirow{2}{*}{$\begin{array}{c}\text { L.I. } \\
\left(\text { Mg.C.ha }^{-1}\right)\end{array}$} & \multirow{2}{*}{$\begin{array}{c}\text { L.S. } \\
(\text { Mg.C.ha-1) }\end{array}$} & \multirow{2}{*}{$\begin{array}{l}\text { E.A. } \\
(\%)\end{array}$} & \multirow{2}{*}{$\begin{array}{c}\text { C.V. } \\
\left(\text { Mg.C.ha }^{-1}\right)\end{array}$} \\
\hline & (ha) & $(\%)$ & & & & & \\
\hline F.A. & $5.278,693$ & 3,93 & 138,57 & 34,64 & 242,50 & 75,00 & 92,32 \\
\hline C.A. & $26.552,58$ & 19,75 & 129,52 & 109,82 & 149,22 & 15,21 & 22,47 \\
\hline F.E.S. & $25.868,217$ & 19,24 & 190,96 & 141,29 & 240,63 & 26,01 & 50,69 \\
\hline F.O.D. & $45.104,101$ & 33,55 & 242,49 & 175,05 & 309,93 & 27,81 & 91,19 \\
\hline F.O.A. & $4.938,304$ & 3,67 & 235,00 & 160,34 & 311,12 & 31,98 & 94,2 \\
\hline V.A. & $26.694,059$ & 19,86 & 154,90 & 134,14 & 175,66 & 13,40 & 23,68 \\
\hline Total & $134.435,954$ & 100 & 188,54 & 143,07 & 234,02 & 24,12 & 56,57 \\
\hline
\end{tabular}

C Médio: estoque médio de carbono (megagramas por hectare); L.I.: limite inferior; L.S.: limite superior; E.A.: erro amostral; C.V.: coeficiente de variação. Estratos: F.A. - Floresta Aluvial; C.A. - Campo Aluvial; F.E.S. - Floresta Ombrófila Aberta com cipó explorada seletivamente; F.O.D. - Floresta Ombrófila Densa; F.O.A. - Floresta Ombrófila Aberta com cipó; V.A. - Várzea Alta.

A variável carbono é diretamente proporcional aos seguintes fatores: área de interesse, número de indivíduos dessa área (densidade) e área basal. Dessa forma, elaborou-se a tabela 3 para efeito de comparação entre a variável de interesse, carbono, e os fatores que a influenciam.

Tabela 3. Efeitos da área basal e densidade sobre a variável carbono.

Table 3. Basal area effects and density over the carbon variable.

\begin{tabular}{|c|c|c|c|c|c|}
\hline \multirow{2}{*}{ Estrato } & \multicolumn{2}{|c|}{ Área } & \multirow{2}{*}{$\begin{array}{c}\text { C } \\
\left(\text { Mg.ha }^{-1}\right)\end{array}$} & \multirow{2}{*}{$\begin{array}{c}\text { Densidade } \\
\left(\text { árv.ha }^{-1}\right)\end{array}$} & \multirow{2}{*}{$\begin{array}{c}\text { Área basal } \\
\left(\mathbf{m}^{2} \cdot \mathbf{h a}^{-1}\right)\end{array}$} \\
\hline & (ha) & $(\%)$ & & & \\
\hline F.A. & $5.278,69$ & 3,9 & 138,57 & 524 & 25,8 \\
\hline C.A. & $26.552,58$ & 19,8 & 129,52 & 485 & 22,3 \\
\hline F.E.S. & $25.868,22$ & 19,2 & 190,96 & 531 & 29,0 \\
\hline F.O.D. & $45.104,10$ & 33,6 & 242,49 & 509 & 37,8 \\
\hline F.O.A. & $4.938,30$ & 3,7 & 235,00 & 603 & 32,6 \\
\hline V.A. & $26.694,06$ & 19,9 & 154,90 & 611 & 27,6 \\
\hline Total & $134.435,95$ & 100,0 & 188,54 & 544 & 28,3 \\
\hline
\end{tabular}

C: estoque de carbono (megagramas por hectare). Estratos: F.A. - Floresta Aluvial; C.A. - Campo Aluvial; F.E.S. - Floresta Ombrófila Aberta com cipó explorada seletivamente; F.O.D. - Floresta Ombrófila Densa; F.O.A. - Floresta Ombrófila Aberta com cipó; V.A. - Várzea Alta.

Intensidade amostral

Através do inventário piloto, estabeleceu-se a intensidade amostral necessária para cada estrato. A intensidade amostral indica o número de parcelas necessário para cada estrato para a realização de um levantamento mais apurado, com erro amostral de 10\%. A tabela 4 resume o número de parcelas necessário para cada tipologia amostrada e o número de parcelas amostradas no inventário piloto. 
Tabela 4. Planejamento do inventário definitivo para um erro amostral de $10 \%$ da média, com $95 \%$ de significância. Variável: estoque de Carbono por hectare.

Table 4. Planning of the definitive inventory for a $10 \%$ average sampling error and $95 \%$ significance. Variable: carbon stock per hectare.

\begin{tabular}{|c|c|c|c|c|}
\hline \multirow{2}{*}{ Estrato } & \multicolumn{2}{|c|}{ Área } & \multirow{2}{*}{$\mathbf{n}^{\circ}$ de parcelas necessário } & \multirow{2}{*}{$\mathrm{n}^{\mathrm{o}}$ de parcelas medidas } \\
\hline & (ha) & $(\%)$ & & \\
\hline F.A. & $5.278,69$ & 3,93 & 12 & 3 \\
\hline C.A. & $26.552,58$ & 19,75 & 15 & 5 \\
\hline F.E.S. & $25.868,22$ & 19,24 & 32 & 4 \\
\hline F.O.D. & $45.104,10$ & 33,55 & 101 & 7 \\
\hline F.O.A. & $4.938,30$ & 3,67 & 11 & 6 \\
\hline V.A. & $26.694,06$ & 19,86 & 16 & 5 \\
\hline Total & $134.435,95$ & 100,00 & 187 & 30 \\
\hline
\end{tabular}

Estratos: F.A. - Floresta Aluvial; C.A. - Campo Aluvial; F.E.S. - Floresta Ombrófila Aberta com cipó explorada seletivamente; F.O.D. - Floresta Ombrófila Densa; F.O.A. - Floresta Ombrófila Aberta com cipó; V.A. - Várzea Alta.

Resultados da análise de tamanho de parcela

Obtiveram-se as fontes de variação aleatória, a variância entre parcelas e a variância entre subparcelas dentro da parcela através da construção de uma tabela de análise de variância com decomposição de soma de quadrados. Essas fontes foram calculadas para área total e para as 6 tipologias encontradas na propriedade. A tabela a seguir demonstra a análise para a área total:

Tabela 5. Análise de variância.

Table 5. Variance analysis.

\begin{tabular}{lccc}
\hline F.V. & G.L. & S.Q. & Q.M. \\
\hline Entre & 29 & 2.600 .605 & 89.676 \\
Dentro & 120 & 1.783 .801 & 120 \\
\hline Total & 149 & 4.384 .406 & 29.426 \\
\hline
\end{tabular}

Por meio das tabelas de análise de variância, área total e por tipologia, calculou-se a variância das subparcelas e o coeficiente de correlação intraclasse. Esses estimadores possibilitaram o cálculo da variância da média amostral, para a área total e para cada tipologia, em termos de megagramas de carbono por hectare. Com a finalidade de se incluir a variável custo para determinação do tamanho ótimo de parcela, determinou-se uma razão de custo de acesso sobre custo de medição com valor 1 , de forma a simular um tempo igual para acesso e medição de parcela.

Através dessa razão e do valor do coeficiente de correlação intraclasse, estabeleceu-se o número de subparcelas (k) a serem utilizadas por tipologia.

Os resultados estão apresentados na tabela a seguir:

Tabela 6. Análise de tamanho de parcela por tipologia e para área total.

Table 6. Portion size by typology and total area analysis.

\begin{tabular}{|c|c|c|c|c|c|c|c|}
\hline \multirow{2}{*}{ Tipologia } & \multirow{2}{*}{ n } & \multicolumn{2}{|c|}{ Análise de var. } & \multirow{2}{*}{$\begin{array}{l}\text { Var. da M.A. } \\
\left(\text { Mg C ha }^{-1)}\right.\end{array}$} & \multirow{2}{*}{$\begin{array}{l}\text { Var. sub. } \\
\text { (Mg.C.ha }{ }^{-1)}\end{array}$} & \multirow{2}{*}{$\begin{array}{c}\text { Coeficiente de } \\
\text { correlação intraclasse }\end{array}$} & \multirow{2}{*}{$\begin{array}{c}\mathrm{K}^{*} \\
(\mathrm{Ca} / \mathrm{Cm}=1)\end{array}$} \\
\hline & & $\mathrm{Se}^{2}$ & $\mathbf{S d}^{2}$ & & & & \\
\hline F.A. & 3 & 44.180 & 7.081 & $2.945,3$ & $14.500,8$ & 0,51 & 0,98 \\
\hline C.A. & 5 & 45.095 & 6.813 & $1.803,7$ & $15.569,4$ & 0,52 & 0,94 \\
\hline F.E.S. & 4 & 12.956 & 10.200 & 647,7 & $10.751,4$ & 0,05 & 4,3 \\
\hline F.O.D. & 7 & 47.970 & 28.280 & $1.370,5$ & $32.218,1$ & 0,12 & 2,67 \\
\hline F.O.A. & 6 & 52.795 & 16.087 & $1.759,8$ & $23.428,2$ & 0,31 & 1,48 \\
\hline V.A. & 5 & 335.235 & 13.235 & $13.409,4$ & $77.635,2$ & 0,80 & 0,4 \\
\hline Total & 30 & 89.676 & 120 & 597,84 & $18.031,21$ & 0,98 & 0,08 \\
\hline
\end{tabular}

$\mathrm{n}$ - $\mathrm{n}^{\circ}$ de parcelas amostradas; $\mathrm{Se}^{2}$ - variância entre parcelas; Sd² - variância dentro da parcela; Var. M.A. - variância da média amostral; Var. sub - variância entre as subparcelas se fossem unidades amostrais aleatórias; F.A. - Floresta Aluvial; C.A. - Campo Aluvial; F.E.S. - Floresta Ombrófila Aberta com cipó explorada seletivamente; F.O.D. - Floresta Ombrófila Densa; F.O.A. Floresta Ombrófila Aberta com cipó; V.A. - Várzea Alta. 
A partir dos valores encontrados para o coeficiente de correlação intraclasse, calculou-se o tamanho de parcela ótimo, em função do número de subparcelas (k), para diferentes razões de custo. A tabela a seguir apresenta os resultados encontrados:

Tabela 7. Tamanho de parcela ideal $\left(\mathrm{n}^{\mathrm{o}} \mathrm{de} \mathrm{k}\right)$.

Table 7. Optimum plot size $\left(\mathrm{n}^{\circ} \mathrm{k}\right)$.

\begin{tabular}{lcccccc}
\hline Tipologia & $\begin{array}{c}\text { Coeficiente de correlação } \\
\text { intraclasse }\end{array}$ & $\mathbf{1}$ & $\mathbf{2}$ & $\mathbf{3}$ & $\mathbf{4}$ & $\mathbf{5}$ \\
\hline F.E.S. & 0,05 & 4 & 6 & 8 & 9 & 10 \\
F.O.D. & 0,10 & 3 & 4 & 5 & 6 & 7 \\
F.O.A. & 0,30 & 2 & 2 & 3 & 3 & 3 \\
C.A. e F.A. & 0,50 & 1 & 1 & 2 & 2 & 2 \\
V.A. & 0,80 & 1 & 1 & 1 & 1 & 1 \\
\hline Área total & 0,98 & 0 & 0 & 0 & 0 & 1 \\
\hline Razão de custos: Custo de acesso / Custo de medição. & & & & &
\end{tabular}

\section{DISCUSSÃO}

\section{Inventário piloto}

A estimativa de estoque de carbono para a parte aérea lenhosa, encontrada no inventário piloto, para a área total, foi de 188,54 megagramas de carbono por hectare, com variação de 143,07 a 234,02 megagramas de carbono por hectare. Valor superior ao encontrado por Gerwing; Vidal (2002), em Paragominas (PA), que estimaram a biomassa viva acima do solo de floresta intacta, mensurando os indivíduos com DAP superior ou igual a $10 \mathrm{~cm}$, em 309 toneladas por hectare, o que corresponderia a 154,5 toneladas de carbono por hectare. No entanto, esses valores encontrados apenas compreendem os indivíduos com DAP superior a $10 \mathrm{~cm}$. Essa estimativa, portanto, é conservadora e subestimada, uma vez que um estudo de Gerwing; Farias (2003) determina que indivíduos com DAP inferior a $10 \mathrm{~cm}$ e cipós representam $19 \%$ da biomassa total acima do solo.

Em relação às tipologias florestais, temos a Floresta Ombrófila Densa e a Floresta Ombrófila Aberta com cipó como as de maior estoque de carbono, respectivamente de 242,49 megagramas de carbono por hectare (variação de 175,05 a 309,93 Mg.C.ha ${ }^{-1}$ ) e 235,73 megagramas de carbono por hectare (variação de 160,34 a 311,12 Mg.C.ha ${ }^{-1}$ ).

Quanto à área basal, esta se mostrou diretamente proporcional ao estoque de carbono. As tipologias com maior estoque de carbono, Floresta Ombrófila Densa e a Floresta Ombrófila Aberta com cipó, foram as que apresentaram maior área basal, com valores respectivamente de $37,8 \mathrm{~m}^{2} \cdot \mathrm{ha}^{-1} \mathrm{e}$ $32,6 \mathrm{~m}^{2} \cdot \mathrm{ha}^{-1}$. No entanto, estes não foram os estratos que apresentaram maior densidade, o que demonstrou que essa variável não pode ser considerada isoladamente para se analisar a biomassa ou estoque de carbono de uma floresta.

Este inventário, por ser tratar de um inventário piloto, em que se busca uma estimativa inicial e informações básicas da floresta, utilizou-se de um baixo número de unidades amostrais. Portanto o erro amostral encontrado de $24 \%$ para $95 \%$ de significância para a variável de interesse não é satisfatório para um inventário definitivo.

Dessa forma, faz-se necessário realizar um inventário definitivo para a obtenção de uma estimativa mais apurada. Vale lembrar que, como inventário piloto, este se mostrou satisfatório, pois determinou o número de unidades amostrais necessárias para um erro amostral predeterminado, estimou de forma inicial o estoque de carbono na parte aérea lenhosa e gerou outras observações necessárias, como a variação existente dentro de cada estrato, para um melhor planejamento do inventário definitivo.

\section{Análise do tamanho de parcela}

A análise de tamanho ótimo de parcela para a área total apresenta um coeficiente de correlação muito elevado, igual a 0,98. Esse resultado se deve à elevada variabilidade encontrada entre as parcelas, uma vez que foram analisadas as 6 tipologias florestais encontradas na propriedade como uma mesma população. Dessa forma, a variabilidade encontrada dentro da parcela torna-se quase desprezível, uma vez que a variância entre parcelas foi de 89,676 Mg.C.ha ${ }^{-1}$, e a variância dentro das parcelas foi de 
$120 \mathrm{Mg}$.C.ha ${ }^{-1}$. Isso contribui para elevar o coeficiente de correlação intraclasse, demonstrando uma máxima homogeneidade dentro da parcela.

Os valores encontrados para a média amostral e para a variância entre subparcelas foram de, respectivamente, 597,84 Mg.C.ha ${ }^{-1}$ e 18.031,21 Mg.C.ha ${ }^{-1}$. Esses valores representam valores elevados. Valores superiores aos encontrados no inventário piloto, cuja amostragem foi realizada através de estraficação, pois se consideram as subparcelas como unidades amostrais em uma amostragem aleatória simple, e dessa forma não ocorre redução da variabilidade, ocasionada pela estratificação.

Quando se inclui a variável custo, sendo esta de valor 1 (custo de acesso/custo de medição), variando até 5 , como demonstrado na tabela 7 , vemos a necessidade de utilização do menor tamanho de parcela possível. Neste caso, variou de 0,08 (Tabela 6) a 1 (Tabela 7) o número de subparcelas a ser utilizado. Deve-se utilizar o menor tamanho de parcela para se ter um maior número de parcelas amostradas, uma vez que a variabilidade está entre as parcelas.

Ao realizarmos a análise por tipologia, em que há efeito da estratificação, a variabilidade entre as parcelas e dentro das parcelas torna-se de mesma grandeza e ocasiona em uma redução sensível do coeficiente de correlação intraclasse. Este resulta em valores de 0,05 a 0,8 em função da tipologia (Tabelas 6 e 7).

A tipologia com maior variabilidade dentro da parcela foi a Floresta Ombrófila Aberta com cipó explorada seletivamente, com coeficiente de 0,05 , o que demonstra grande variabilidade. Isso devido ao fato de essa tipologia ter sido explorada para a retirada de madeira (efeito antrópico). Portanto, em uma mesma parcela pode-se amostrar locais com ou sem danos provocados pela exploração seletiva. A Várzea Alta foi a tipologia com maior variabilidade entre as parcelas (coeficiente de 0,8), devido à homogeneidade da tipologia. As demais tipologias apresentaram valores para o coeficiente próximos entre si, e podem ser visualizados na tabela 6 .

Ao se incluir a variável custo, temos diferentes tamanhos de parcela em função do número de subparcelas, como demonstrado na tabela 7. Nessa tabela, podemos observar custos variando de 1 a 5 para os coeficientes das tipologias amostrados.

Para efeito de planejamento do inventário definitivo, deve-se levar em conta a tipologia de maior expressão em termos de área, no caso a Floresta Ombrófila Densa, que possui 33\% da área total, uma vez que se utilizará de amostragem estratificada e unidades amostrais de mesmo tamanho. Dessa forma, a dimensão das unidades amostrais a serem utilizadas no inventário definitivo será de 10 x $200 \mathrm{~m}$ ou 4k, pois se considerou para o inventário definitivo a razão custo igual a 2.

O gráfico a seguir demonstra o comportamento encontrado na análise de que quanto maior for o custo maior será o tamanho da parcela, em função do número de subparcelas utilizado. Portanto, quanto maior a dificuldade de acesso à parcela, maior a necessidade de se utilizar um tamanho maior de parcela. A análise do gráfico também nos permite observar que esse comportamento é em função da homogeneidade da floresta amostrada, uma vez que, quanto maior for a homogeneidade da floresta (maior coeficiente), menor será a elevação do tamanho de parcela. Essa discussão pode ser melhor visualizada através das curvas da Floresta Ombrófila Densa e Várzea Alta encontradas na figura 1.

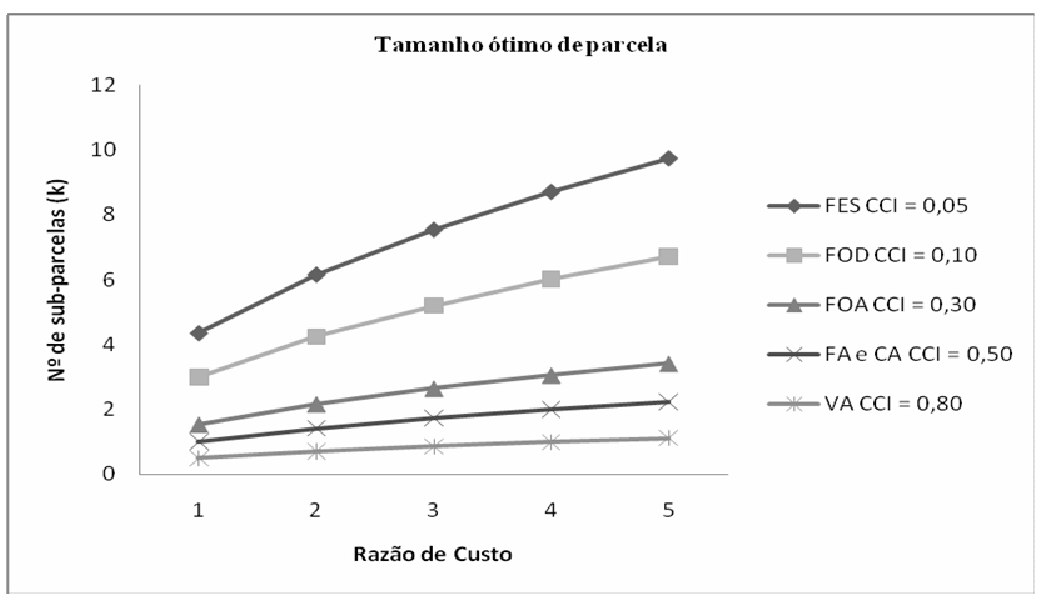

Figura 1. Gráfico de tamanho de parcela ótimo em função dos custos de medição e acesso as parcelas. Figure 1. Optimum plot size by measuring costs and accessibility of the portions. 
Em que: $\mathrm{CCI}=$ coeficiente de correlação intraclasse;

F.A. = Floresta Aluvial; C.A. $=$ Campo Aluvial; F.E.S. $=$ Floresta Ombrófila Aberta com cipó explorada seletivamente; F.O.D. = Floresta Ombrófila Densa; F.O.A. = Floresta Ombrófila Aberta com cipó; V.A. = Várzea Alta.

\section{CONCLUSÕES}

- Este estudo demonstrou a importância da estratificação como ferramenta para redução da variabilidade entre as parcelas e a eficácia do método utilizado como ferramenta para o planejamento do inventário definitivo.

- O método se mostrou eficaz, uma vez que permitiu a observação da variabilidade existente em cada tipologia entre as parcelas amostradas e dentro delas, além de incluir a variável custo na análise do tamanho de parcela. Através deste método, pode-se também definir o tamanho ideal de parcela para o estudo, em função da variabilidade da população estudada e dos custos de acesso e medição das unidades amostrais.

- Estimou-se a média do estoque de carbono na parte aérea lenhosa em 188,54 megagramas de carbono por hectare, com variação de 143,07 a 234,02 megagramas de carbono por hectare. O tamanho ótimo da unidade amostral a ser utilizada no inventário amostral definitivo será de 10 x $200 \mathrm{~m}\left(2000 \mathrm{~m}^{2}\right)$.

\section{AGRADECIMENTOS}

Ao IPÊ (Instituto de Pesquisas Ecológicas), por viabilizar este estudo, e ao Dr. Eduardo Ditt, por ser o mentor do projeto ao qual este trabalho está inserido. Agradecemos à Martins Agropecuária, por financiar o estudo e pelo apoio logístico.

\section{REFERÊNCIAS}

BATISTA, J. L. F. Notas para a disciplina LCF-764 - Métodos de Amostragem em Levantamentos Florestais, do Programa de Pós-Graduação em Recursos Florestais, ESALQ, Universidade de São Paulo. 2006.

EMBRAPA, Centro Nacional de Pesquisas de Solos (Rio de Janeiro, RJ). Sistema brasileiro de classificação de solos. Brasília: EMBRAPA Produção de informação; Rio de Janeiro: EMBRAPA Solos, 1999. Xxvi, $412 \mathrm{p}$.

FEARNSIDE, P. M. Efeitos do uso da terra e manejo florestal no ciclo de carbono na Amazônia brasileira. In: MMA. Causas e dinâmica do desmatamento na Amazônia. Brasília: MMA, 2001, p. 173-196.

GERWING, J.; LOPES, D. Integrating liana abundance and forest stature into an estimate of total aboveground biomass for an eastern Amazonian forest. Journal of Tropical Ecology. 2000. 16: 327-335.

GERWING, J.; VIDAL, E. Degradação de florestas pela exploração madeireira e fogo na Amazônia. Jeffrey Gerwing \& Edson Vidal. Série Amazônia n. 20 - Belém: Imazon, 2002. 26 p.

HIGUCHI, N.; CHAMBERS, J.; SANTOS, J. dos; RIBEIRO, R. J.; PINTO, A. C. M.; SILVA, R. P. da; ROCHA, R. M.; TRIBUZY, E. S. Dinâmica e balanço do carbono da vegetação primária da Amazônia Central. Revista Floresta, Curitiba-PR. v. 34. n. 3, p. 295-304, Set/Dez 2004.

HIGUCHI, N.; CARVALHO JR., J. A. Biomassa e conteúdo de carbono de espécies arbóreas da Amazônia. In: Emissão x sequestro de $\mathbf{C O}_{2}$ : uma nova oportunidade de negócios para o Brasil. Porto Alegre. Anais. Companhia Vale do Rio Doce, Rio de Janeiro, pp. 125-153. 1994.

INPE - Instituto Nacional de Pesquisas Espaciais. Desflorestamento na Amazônia. Disponível em: http://www.obt.inpe.br/prodes/index.html. Acesso em 20 de março de 2008. 
MINISTÉRIO DA CIÊNCIA E TECNOLOGIA - MCT. Primeiro inventário brasileiro de emissões antrópicas de gases de efeito estufa - Relatórios de referência - Emissões de carbono por conversão de florestas e abandono de terras cultivadas. Brasília, DF, Brasil. 2006. 100 p.

QUEIROZ, W. T. Efeitos da variação estrutural em unidade amostral na aplicação do processo de amostragem em conglomerados nas florestas do Planalto do Tapajós. Revista Floresta, Curitiba, v. 8, n. 1, p. 19-23, 1977.

RADAM. Levantamento de recursos naturais. Ministério das Minas e Energia, Departamento Nacional de Produção Mineral. Brasília. 1974.

SANTOS, S. R. M.; MIRANDA, I. S.; TOURINHO, M. M. Estimativa de biomassa de sistemas agroflorestais das várzeas do rio Juba, Cametá, Pará. Acta Amazônica, v. 34(1) 2004: 1- 8. 2004.

VIDAL, E.; GERWING, J. J. (orgs.). Ecologia e manejo de cipós na Amazônia Oriental. Belém: Imazon, 2003, p. 85-91. 